\title{
BEHAVIOR OF THE NORTH AMERICAN TERMITE TENUIROSTRITERMES TENUIROSTRIS, WITH SPECIAL REFERENCE TO THE SOLDIER FRONTAL GLAND SECRETION, ITS CHEMICAL COMPOSITION, AND USE IN DEFENSE ${ }^{2}$
}

\author{
By W. L. Nutting, ${ }^{3}$ M. S. Blum ${ }^{4}$ and H. M. Fales ${ }^{5}$
}

\section{INTRODUCTION}

Tenuirostritermes is a small genus of Neotropical termites with two species ranging northward into warm temperate, semi-arid areas of southwestern Texas [cinereus (Buckley)] or beyond into southeastern Arizona [tenuirostris (Desneux)]. As a member of the Nasutitermitinae, it is somewhat more primitive than the very large and well-known tropicopolitan genus, Nasutitermes. The subfamily, containing the most highly specialized members of the Termitidae, is the largest in the order Isoptera. The major specialization within the subfamily has involved gradual reduction of the soldier mandibles to non-functional stubs with concomitant development of a small projection on the front of the head into a long, attenuated snout or nasus. The frontal gland, occupying most of the bulbous posterior of the head capsule, elaborates a defensive secretion which can be forcibly ejected through the frontal pore at the tip of the nasus by contraction of powerful mandibular muscles. This fontanellar gun represents the apex of sophistication among the varied chemical defense mechanisms of the termites. The zoogeography and affinities of the nasutitermitine genera have been discussed by Emerson ( 1955) and Krishna (1970) and their defensive behavior by Ernst (1959), Moore (1969) and Wilson (197I). Light and Weesner (1955)

\footnotetext{
${ }^{1}$ Termitidae, Nasutitermitinae.

2Journal Paper No. 2269 of the Arizona Agricultural Experiment Station. The work on which this report is based was carried out as a part of the U.S./I.B.P. Desert Biome, and was supported (in part) by National Science Foundation Grant No. GB-15886.

${ }^{3}$ Department of Entomology, University of Arizona, Tucson 85721 .

${ }^{4}$ Department of Entomology, University of Georgia, Athens 30601.

${ }^{5}$ Laboratory of Chemistry, National Heart and Lung Institute, Bethesda, Md. 20014.

Manuscript received by the editor February 22, 1974.
} 
and Weesner (1953, 1970) have made the only major contributions on the general biology of $T$. tenuirostris, and Nutting (1970) has summarized the information on its foraging behavior.

\section{Materials And Methods}

Seven collections of the termites were made in early September, 1972, on the Santa Rita Experimental Range, elevation between 945 and $1220 \mathrm{~m}$, ca. $45 \mathrm{~km}$ south of Tucson, Arizona. The area is a shrub-invaded desert grassland ecotone, characterized by scattered trees, shrubs and cacti. Four groups were taken from under stones during one afternoon and three nearly complete foraging groups were taken on the soil surface near midnight. Termites and a minimum of soil were quickly scooped up with a trowel and placed in a large enameled tray. A few hours later the termites were separated from soil and debris by sifting and hand-picking. To determine soldier/ worker ratios, these castes were counted in each of the two combined collections, those from under stones, and those taken on the surface. Several hundred of these soldiers and workers were reserved for chemical analyses.

A small foraging group was collected later for behavioral studies. They were supplied with fine, dry native vegetation and survived reasonably well in the laboratory for about three weeks in a plastic petri dish of moist soil. A few minor workers of the myrmicine ant, Pheidole desertorum Wheeler, were also collected in the same area and maintained for the observation of termite-ant encounters. Although most species of Pheidole are reportedly seed gatherers rather than habitual predators, this was apparently of no consequence in the artificial situations described below.

No encounters between termite foraging groups and small arthropod predators were seen in the field. A few random encounters were staged in the laboratory by introducing individual ants into the dish containing the small group of termites. The defensive behavior of the soldiers was observed in detail under low magnifications of a stereomicroscope, during individual soldier-ant encounters contrived as follows: Single living ants were mounted in a natural position on glass slides with a small drop of rubber cement. Slide and ant were then placed on the soil in the observation chamber with the termites. In this distinctly one-sided situation, one or more soldiers invariably located and attacked the ant within a few minutes.

Attacks by five different soldiers were quite literally recorded on 
separate slides in the form of discrete threads of frontal gland secretion which they had fired in the general direction of the ants. The volume of most of these shots was calculated from measurements made of the threads with an ocular micrometer under a compound microscope. Drawings to illustrate the variation of individual shot patterns were made with the aid of a camera lucida on the same microscope. The fate of a few ant victims was followed until their death and compared with that of normal ants which were isolated and allowed to die of starvation and desiccation.

For the chemical analyses 600 living soldiers were placed in reagent $n$-pentane. Although it had been determined that the heads of the soldiers were the primary source of the odorous defensive compounds, 400 living workers were also extracted for comparative purposes. The extracts were concentrated under vacuum and analyzed on a gas chromatograph interfaced to an LKB-900o mass spectrometer. A 4-meter column of IO $\%$ SP-IOOO on 80/100 mesh Supelcoport operated isothermally at $65^{\circ} \mathrm{C}$ was employed for all analyses.

\section{RESULTS}

Foraging behavior. - $T$. tenuirostris forages in the open on the soil surface, mainly at night in southern Arizona as we have recently established, but it is also active on cloudy days, at least in western Mexico (Nutting, r970). The following account of its general foraging behavior is a synthesis of observations made on about I2 different groups at the Santa Rita Experimental Range during September-October, I972.

Workers presumably open one or more access holes to the surface, but the soldiers are generally the first out and the last to return underground during bouts of surface activity. As many as IOO or more soldiers and very few workers may congregate within a 5- to IO-cm radius of the hole prior to foraging. Little organization is at first apparent except that many of the soldiers may be standing on the alert with heads pointed peripherally. One or more discrete foraging columns eventually emerge from such unorganized, milling masses, perhaps after the soldiers are joined by a critical number of workers. Once in motion, columns up to six workers wide move quickly in an ant-like manner, and show very tight trail-following behavior. While soldiers move out with the workers, they eventually take up stations at $\mathrm{I}-$ to $2-\mathrm{cm}$ intervals on either side of, and ca. I cm 
from, the worker traffic. Columns occasionally branch and have been observed as long as ca. $2 \mathrm{~m}$.

Irregular craters of soil, up to $8 \mathrm{~cm}$ in diameter and $\mathrm{I} \mathrm{cm}$ high, are often thrown up around the holes during periods of surface activity. Ground-level runways radiating from the hole may be bridged over to transform a crater into a rough pile of soil 2 to $3 \mathrm{~cm}$ high. Since individuals of this species are relatively small (length of soldier, $3.0 \mathrm{~mm}$; of worker, $4.5 \mathrm{~mm}$ ), access holes as large as $5 \mathrm{~mm}$ in diameter probably provide for efficient, emergency re-entry of large numbers of foragers in a very short time. Workers have been observed to close the exposed holes shortly after the conclusion of surface activity and, although a few soldiers remain in and around the hole during closure, none was ever left outside. The same holes are apparently used repeatedly, at least for periods of several weeks.

The high proportion of soldiers in the foraging groups indicates the relative importance of this caste in those species of termites which routinely forage on exposed trails. The four combined groups collected from colonies beneath stones contained 545 individuals with a soldier:worker ratio of $\mathrm{I}: 3.82(20.7 \%$ soldiers $)$. Three combined foraging groups contained I,549 individuals with a soldier:worker ratio of I:I.23 ( $44.9 \%$ soldiers). A single foraging group of 230 , perhaps recently organized, had a ratio of I soldier to 0.40 worker ( 7 I. $3 \%$ soldiers).

Soldier behavior. - Whenever the laboratory group of soldiers and workers was disturbed by jarring or removing the cover of their container, several soldiers, with antennae raised and waving, congregated on the edges of objects and on elevated vantage points. Individual workers of the ant, Pheidole desertorum (ca. $3.5 \mathrm{~mm}$ long), introduced into this situation were quickly fired on at very close range by several soldier termites in rapid succession. The appendages of such victims were almost completely immobilized, within ro sec or less, by the viscous, glue-like threads thrown over them.

Further details of soldier defensive behavior are based on observations made during encounters with living ant workers fixed to glass slides. Although blind, the soldiers presumably orient toward such threats by olfactory or auditory cues. An alerted soldier closes rapidly on any potential target and may actually touch it for an instant with its antennae before firing - from a distance of ca. $0.5-3.0 \mathrm{~mm}$ ). As it fires, it may jerk forward or backward, in position, and may or may not then oscillate to-and-fro one or more times. This apparently insignificant bit of behavior greatly enhances the effectiveness of the 


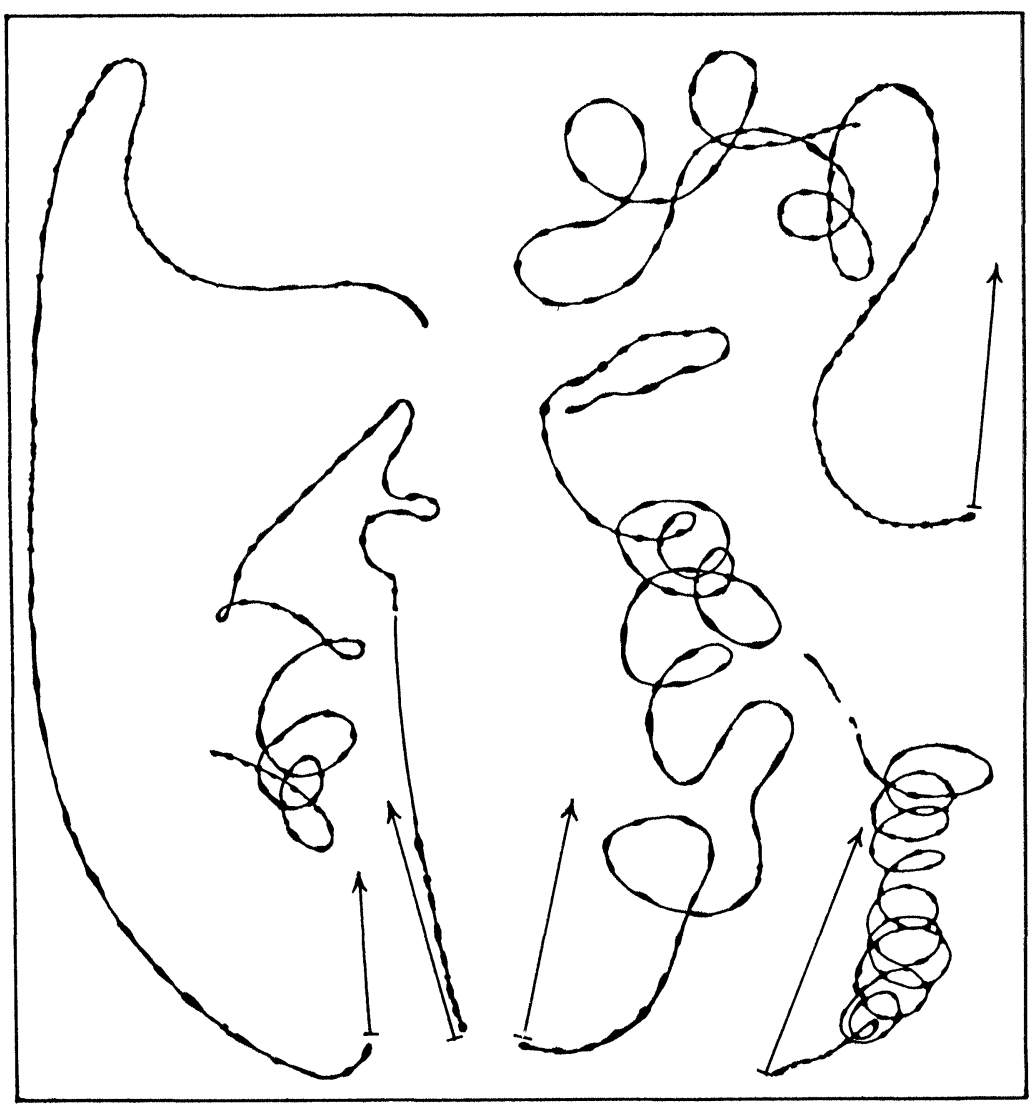

Fig. 1. Patterns of the threads of frontal gland secretion fired by five different soldiers of Tenuirostritermes tenuirostris at living ants fixed to glass slides. Arrows show direction of target and scale of $1 \mathrm{~mm}$. 
Table 1. Measurements of shots or threads fired by four soldiers of Tenuirostritermes tenuirostris at fixed, living ants in the laboratory.

\begin{tabular}{ccccc}
\hline $\begin{array}{c}\text { Soldier } \\
\text { Number }\end{array}$ & $\begin{array}{c}\text { Shot } \\
\text { Number }\end{array}$ & $\begin{array}{c}\text { Av. Diameter } \\
(\mathrm{mm})\end{array}$ & $\begin{array}{c}\text { Length } \\
(\mathrm{mm})\end{array}$ & $\begin{array}{c}\text { Volume } \\
\left(\mathrm{mm}^{3}\right)\end{array}$ \\
\hline 1 & 1 & 0.020 & 19.650 & 0.0062 \\
& 2 & 0.015 & 11.425 & 0.0020 \\
& 3 & 0.015 & 10.475 & 0.0019 \\
& 4 & 0.015 & 7.550 & 0.0013 \\
& 5 & 0.015 & 5.100 & 0.0009 \\
2 & 6 & 0.015 & 2.500 & 0.0004 \\
& 1 & 0.020 & 9.025 & 0.0028 \\
3 & 2 & 0.020 & 7.300 & 0.0023 \\
& 1 & 0.020 & $7.200 *$ & 0.0023 \\
& 2 & 0.020 & 4.625 & 0.0015 \\
4 & 3 & 0.020 & 1.725 & 0.0005 \\
& 1 & $*$ & & \\
& 2 & 0.020 & 0.900 & 0.0003 \\
\hline
\end{tabular}

* Shot entirely on ant and not traceable, or partly on ant and measurement only approximate.

soldier's shot by throwing a bight, or even one or more loops, in the thread (Fig. I). Attacks by as many as six soldiers from different directions were invariably fatal to an ant. Soldiers often examined victims with their antennae for up to a minute, occasionally becoming temporarily entangled themselves. They were never seen to wipe the nasus on the substrate after any of this activity.

In unstaged encounters, soldiers usually fired but once at an ant; however, by carefully prodding and exciting the fixed ants, individual soldiers were induced to fire from one to six additional shots at them. Data on the shots recorded on and near four such ants are summarized in Table I. It was impossible to determine the order of shots fired by individual soldiers, but those of greater diameter and length are probably the ones fired at or near the beginning of an encounter. Longer shots often began with a series of droplets, and occasionally contained short breaks in the thread. It would have been interesting to determine what percent of their glandular holding capacity had been spent in these individuals, but drought conditions during seasons of activity have since prevented further collections.

Although the ant victims were physically immobilized within a few seconds, they also appeared to be adversely affected by some of the chemical components of the soldier secretion, probably the terpenes. 
They lay very quiet, moving their appendages but little even when prodded. Their struggles were very feeble after $\mathrm{I} .5 \mathrm{hr}$, while only occasional, slow contractions could be elicited after $4 \mathrm{hr}$. They appeared essentially dead after 5-6 hr. By comparison, normal ants, similarly confined without food or water, remained so for 5-IO hr, showed postural difficulties after IO-I2 hr, responded vigorously to prodding for as long as $24 \mathrm{hr}$, and did not appear to be dead until 24-33 hr after confinement.

Chemical Analyses. - Three compounds accounted for over $90 \%$ of the low boiling volatile compounds which were detected in the extracts of the soldiers. Based on the congruencies of their gaschromatographic retention times and mass spectra, the volatiles were identified as $\alpha$-pinene, myrcene, and limonene. The mole percentages of the compounds were: $\alpha$-pinene $62 \%$, myrcene $27 \%$, and limonene I $\%$. None of these monoterpene hydrocarbons was detected in the extracts of the workers.

\section{Discussion}

Ernst ( 1959) was inclined to believe that the frontal gland secretion of soldiers of a Nasutitermes sp. from the Ivory Coast was essentially non-toxic and that it functioned primarily to entangle its enemies. He did not rule out the possibility of an insecticidal effect. Considering that normal worker ants survived without food or water 4 to 6 times as long as those immobilized by the T. tenuirostris soldier secretion, we feel that the terpenoid components of its secretion are definitely toxic.

Ernst also observed that the secretion fired by one of his Nasutitermes soldiers stimulated nearby soldiers to fire, thus suggesting that it contains volatiles which act as an alarm pheromone. On the basis of his own work with several Australian species of Nasutitermes, Moore (1969) has suggested that $\alpha$-pinene might serve as such a pheromone. This compound probably serves a similar function in Trinervitermes geminatus Wasmann (Nasutitermitinae) according to Quennedey (1973). Although we have not investigated this point, our observations suggest that any such alarm signal in the secretion of $T$. tenuirostris must act very briefly indeed. In a number of laboratory encounters between soldiers and free ants, several soldiers might fire once each on a single ant within a few seconds; however, late arrivals usually examined the resulting immobilized ants, but never fired on them. 
Moore (1968) determined that both limonene and $\alpha$-pinene were rather typical components of termitid soldier secretions whereas myrcene was detected only in one species of Amitermes. Vrkoc et al. have recently reported the major volatile components in the soldier frontal gland secretion of Nasutitermes rippertii to be $\alpha$ - and $\beta$ pinene and limonene, with myrcene among six minor constituents. Similarly, with $N$. costalis they found $\alpha$ - and $\beta$-pinene and limonene among six major constituents of the secretion, and myrcene again among three minor components. However, although it is evident that monoterpene hydrocarbons are rather characteristic defensive products of nasute soldiers, these compounds do not appear to have a widespread distribution in the Insecta. Indeed, with the exception of the myrmicine ant Myrmicaria natalensis F. Smith, which produces limonene in its poison gland (Grünanger et al., 1960), monoterpene hydrocarbons have not been identified in any other insect taxa.

By taking high speed motion pictures of Nasutitermes soldiers attacking vestigial-winged Drosophila, Ernst (1959) determined that they move rapidly forward and backward (only once?) in delivering the jet of frontal gland secretion. He also observed one soldier to move its head from side to side during an attack. Our tracings of the shot patterns (Fig. I) show that either or both of these movements are also used by soldiers of $T$. tenuirostris to increase the effectiveness of their defense. The basic oscillatory behavior probably represents the jerking or rocking movements which termites commonly exhibit in mild alarm situations. We have also shown that soldiers are capable of firing more than once, if sufficiently alarmed, and certainly do not deliver the entire contents of the frontal gland in a single discharge as Ernst suggested.

Many authors have stated that ants are the chief predators of social insects, with the termites not the least among their prey (Wilson, I97I). There can be little doubt that the nasute soldier is a highly effective defender of the colony against arthropod predators close to the size range of the termites themselves. A large force of nasutes would seem to be of critical importance in protecting the workers on their food-gathering expeditions, particularly those that forage in the open as does $T$. tenuirostris. However, this common assumption apparently rests largely on casual, subjective observations and circumstantial evidence of the type presented here. Quantitative data required to prove this assumption are not available and would be extremely difficult to obtain. 
The high proportion of soldiers maintained by T. tenuirostris, and presumably many other free-foraging termites, certainly attests to their great importance in the colony. Our figure of $20 \%$ soldiers in combined collections from four different colonies is in fair agreement with Light and Weesner (1955) who determined that incipient colonies of this species usually contained between 25 and $33 \%$ soldiers. Three of our foraging groups combined contained $44.9 \%$ soldiers, while a single group contained 71.3\%. Ernst (1959) reported 70 to $90 \%$ soldiers in outer portions of his laboratory colony of Nasutitermes sp. from the Ivory Coast. Although demands on the defensive capabilities of the soldiers underground must be trivial or rare, indeed, these figures show that a very high proportion of soldiers is mobilized for foraging parties.

This situation is in striking contrast to that in another subterranean termitid, Gnathamitermes perplexus (Banks) (Amitermitinae), which is very common over the range of $T$. tenuirostris in southern Arizona. This species forages widely on the surface under cover of thin, soil sheeting which it builds over all types of dead plant material (Collins et al., 1973). Based on 74 foraging groups, the average soldier:worker ratio is $\mathrm{I}: 89$ ( I.I I \% soldiers). Individual groups ranged from I to IO3I termites and contained from 0.0 to 9.10\% soldiers (Nutting and Haverty, unpublished).

During the few hours of field observations on the above-ground activities of $T$. tenuirostris, no encounters with ants or other small predators were seen. However, the presence of an impressive ant fauna in our study area lends further credibility to the importance of the soldier caste in the economy of this termite. In a preliminary study of the ants on the Santa Rita Experimental Range, Gaspar and Werner (unpublished) list 33 species, with high populations of Crematogaster coarctata vermiculata Emery and Forelius foetidus (Buckley), and estimate I753 nests/ha for all species. About one fourth of the species are regular predators, while at least an additional third are occasional predators or at least feed on animal matter. Many of them forage at night during the summer rainy season when Tenuirostritermes is also most active on the surface. Although we have no estimates of colony size or density for the termite, its colonies are fairly common in the area and must contain several thousand individuals. 


\section{AcKnowledgments}

We wish to thank Dr. Ch. Gaspar, Laboratoire de Zoologie générale et de Faunistique, Faculté des Sciences Agronomiques de l'Etat, Gembloux, Belgium, for identifying the ant used for our laboratory observations, and Mr. Michael I. Haverty, Research Associate, Department of Entomology, University of Arizona, for his assistance in collecting the termites.

\section{Literature Cited}

Colins, M. S., M. I. Haverty, J. P. LaFage and W. L. Nutting.

1973. High temperature tolerance in two species of subterranean termites from the Sonoran Desert of Arizona. Environ. Entomol. 2: 1122-1123.

EMERSON, A. E.

1955. Geographical origins and dispersions of termite genera. Fieldiana: Zool. 37 : 465-521.

ERNST, E.

1959. Beobachtungen beim Spritzakt der Nasutitermes-Soldaten. Rev. Suisse Zool. 66 : 289-295.

Grünanger, P., A. Quilico and M. Pavan.

1960. Sul secreto odoroso del formicide Myrmicaria natalensis Fred. Accad. Nazion. Lincei 28: 293-300.

Krishna, K.

1970. Taxonomy, phylogeny, and distribution of termites, pp. 127-152. In "Biology of termites," vol. 2, (K. Krishna and F. M. Weesner, eds.). Academic Press, New York.

Light, S. F., AND F. M. WeEsner.

1955. The incipient colony of Tenuirostritermes tenuirostris (Desneux). Insectes Sociaux 2: 135-146.

MOORE, B. P.

1968. Studies on the chemical composition and function of the cephalic gland secretion in Australian termites. J. Insect Physiol. 14: 33-39.

1969. Biochemical studies in termites, pp. 407-432. In "Biology of termites," vol. 1, (K. Krishna and F. M. Weesner, eds.). Academic Press, New York.

Nutting, W. L.

1970. Free diurnal foraging by the North American nasutiform termite, Tenuirostritermes tenuirostris (Isoptera: Termitidae). Pan-Pacific Entomol. 46: 39-42.

Quennedey, A.

1973. Observations cytologiques et chimiques sur la glande frontale des termites. Internat. Union for the Study of Social Insects, Proc. VIIth Internat. Congress, London, 10-15 Sept., 1973. pp. 324-326. 
VRKoč, J., K. UbiK, L. Dole Js and I.HrdÝ.

1973. On the chemical composition of frontal gland secretion in termites of the genus Nasutitermes ( $N$. costalis and $N$. rippertii; Isoptera). Acta Entomol. Bohemoslov. 70:74-80.

WEESNER, F. M.

1953. The biology of Tenuirostritermes tenuirostris (Desneux) with emphasis on caste development. Univ. Calif. Publ. Zool. 57: 251-302.

1970. Termites of the Nearctic Region, pp. 477-525. In "Biology of termites," vol. 2, (K. Krishna and F. M. Weesner, eds.). Academic Press, New York.

Wilson, E. O.

1971. "The insect societies." The Belknap Press of Harvard Univ. Press, Cambridge, Mass. 548 pp. 

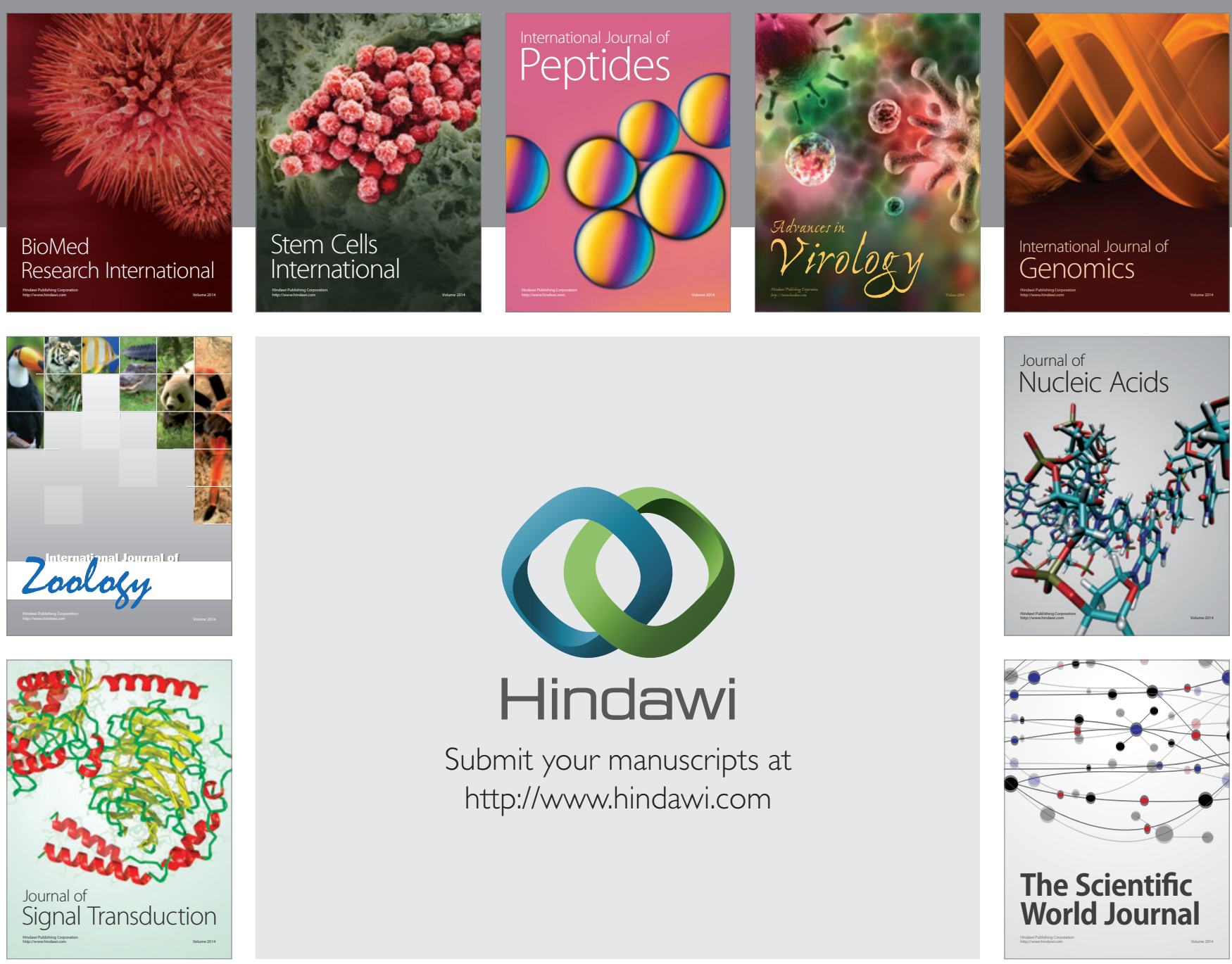

Submit your manuscripts at

http://www.hindawi.com
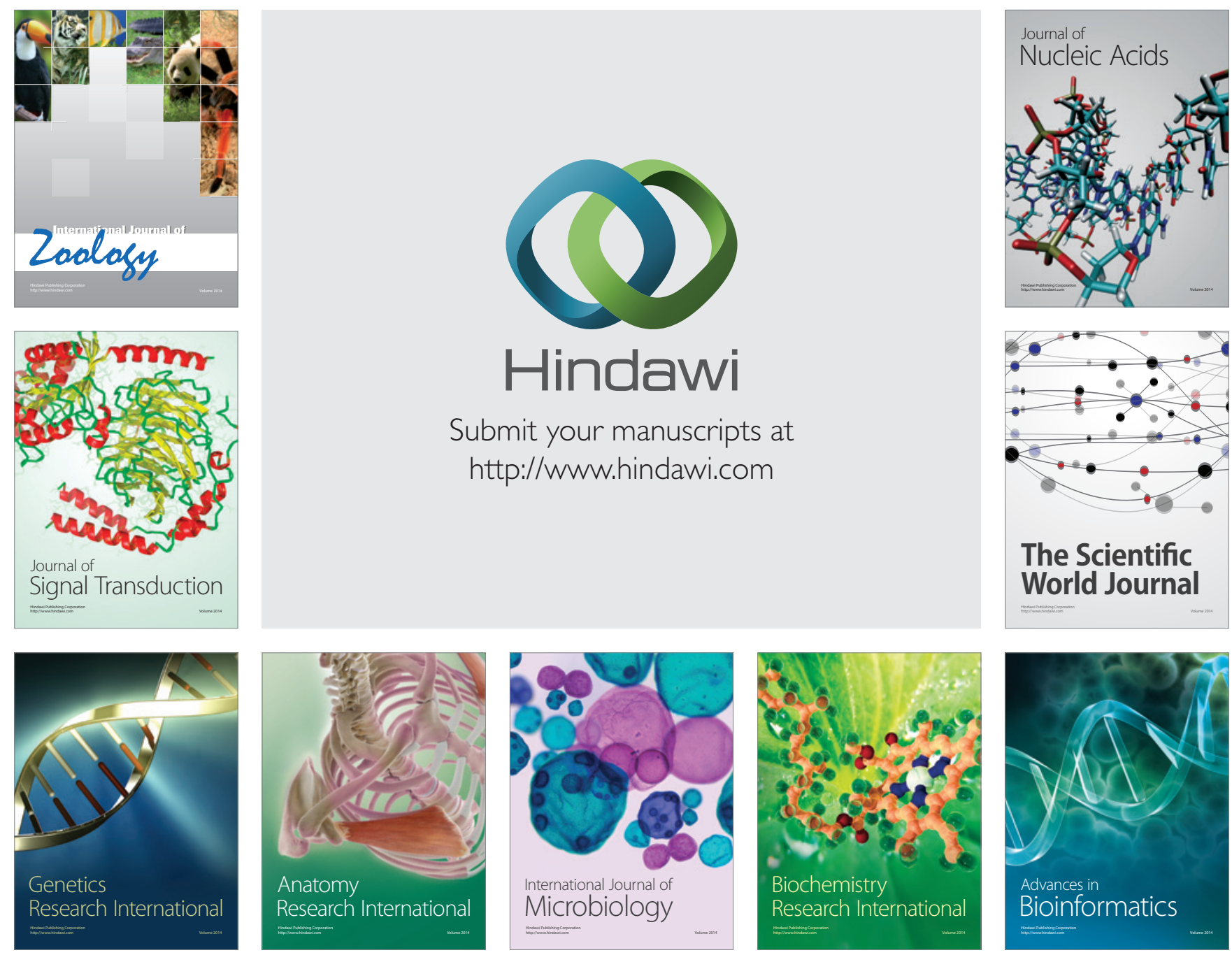

The Scientific World Journal
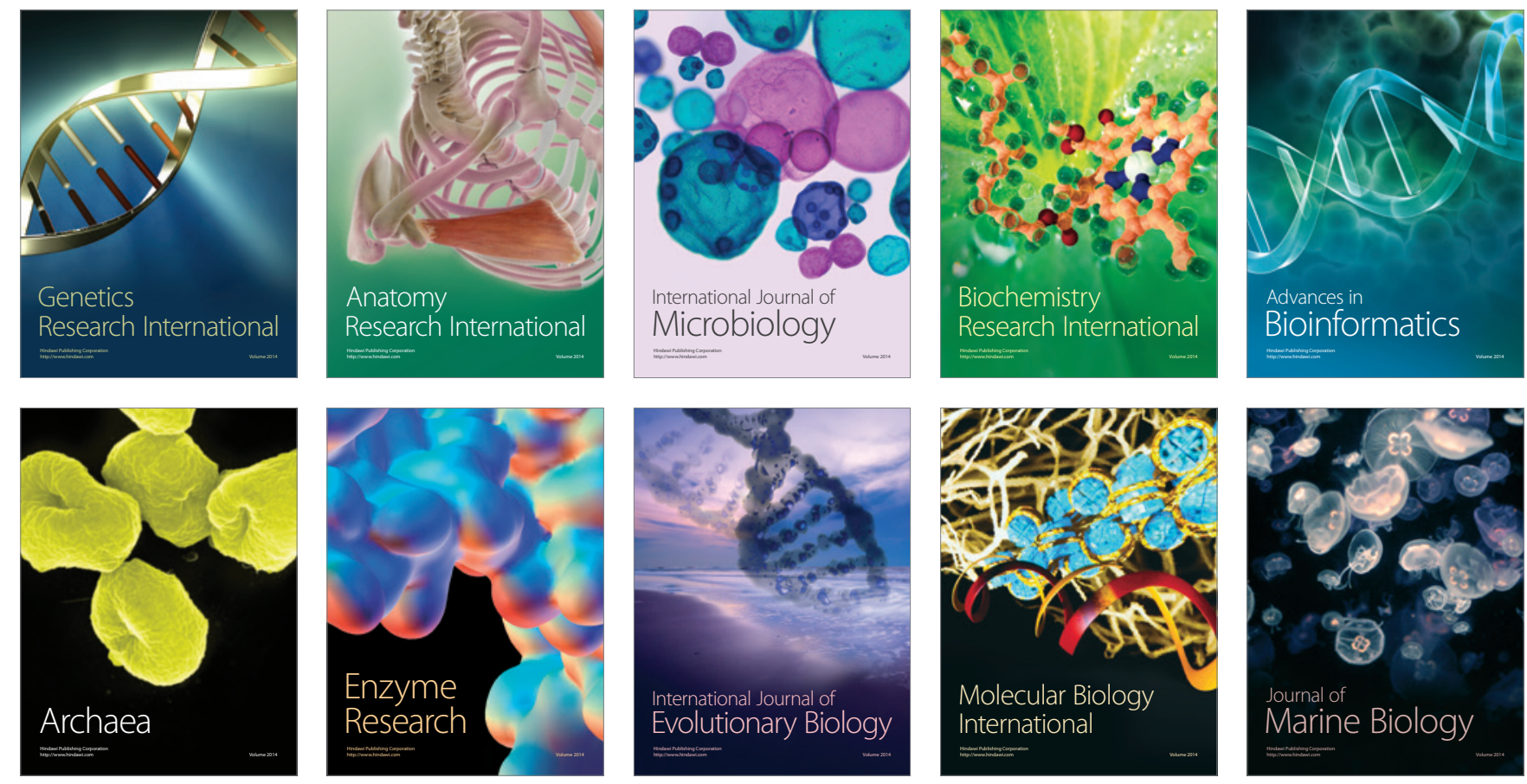